\title{
Enhanced Surface Passivation of Subnanometer Silicon Dioxide Films by Superacidic Treatments
}

\author{
Nicholas E. Grant,* Sophie L. Pain, Joshua T. White, Marc Walker, Ivan Prokes, and John D. Murphy
}

Cite This: ACS Appl. Energy Mater. 2022, 5, 1542-1550

Read Online

ABSTRACT: Subnanometer-scale silicon dioxide $\left(\mathrm{SiO}_{2}\right)$ films are frequently present before, during, and after silicon device processing, yet they offer minimal surface passivation and can detrimentally impact subsequent processing steps. Here we develop a process whereby the surface passivation of nanometer and subnanometer $\mathrm{SiO}_{2}$ films is enhanced by up to 2 orders of magnitude by a simple room temperature treatment using the superacid bis(trifluoromethane)sulfonimide (TFSA, sometimes TFSI). By accurately modeling the effective lifetime curves corresponding to the superacid treated $\mathrm{SiO}_{2}$ samples, we have determined that the enhanced passivation is mainly due to a reduction in the interface defect density $\left(D_{\mathrm{it}}\right)$ at the $\mathrm{Si} / \mathrm{SiO}_{2}$ interface, with a minor contribution also arising from the presence

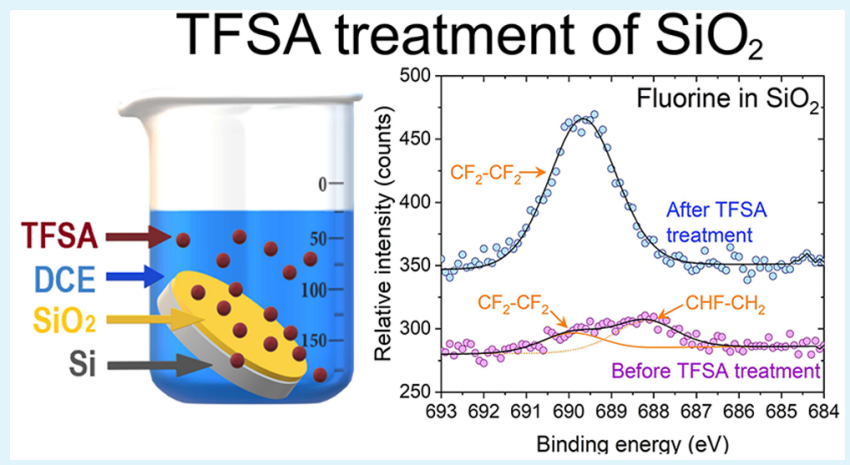
of negative charge. X-ray photoelectron spectroscopy of the treated $\mathrm{SiO}_{2}$ films reveals the presence of fluorine, and this, along with hydrogen, is a strong candidate for the chemical passivation of defects at the $\mathrm{Si} / \mathrm{SiO}_{2}$ interface. Post treatment, the $\mathrm{SiO}_{2}$ films show short time scale electronic instability, whereby a degradation and then recovery are observed over a period of $1-10 \mathrm{~h}$ which is attributed to variations in the $D_{\mathrm{it}}$ as determined from our analysis of the injection-dependent lifetime data. Following the instability period, the surface passivation remains relatively stable for days. Nuclear magnetic resonance measurements of superacid-based solutions reveal that electron-donating solvents should be avoided, as they exacerbate surface passivation instabilities. The results presented demonstrate that simple strategies can be used to enhance the passivation properties of ultrathin films greatly, which in the age of nanotechnology could offer benefits to device performance in a range of applications including solar cells and batteries.

KEYWORDS: lifetime, nanometer, passivation, silicon dioxide, superacid

\section{INTRODUCTION}

The existence of ultrathin $(<1 \mathrm{~nm})$ native oxides on semiconductor surfaces which form from storage in ambient conditions has often reflected negatively on electronic device performance. In particular, native oxides prevent the growth (or deposition) of high quality films on the semiconductor surface and consequently result in poor film adhesion, an increase in contact resistance, and enhanced surface recombination. ${ }^{1}$ As a result, for silicon in particular, native oxides have undergone extensive investigation to prevent/inhibit their formation and therefore improve device yield and performance.

While the native oxide has long been considered a pest for electronic devices, it does have one substantial advantage over other thin film growth methods, insofar as it readily grows uniform subnanometer thin films on silicon surfaces, which in the age of nanotechnology should not be overlooked. ${ }^{1,2}$ The challenge therefore is not how to remove the native oxide, but how to replicate its growth on much shorter time scales and how to improve the electronic properties of the oxide to reduce contact resistance and surface recombination (similar to that achieved by much thicker thermally grown $\mathrm{SiO}_{2}$ ), thereby boosting device performance rather than hindering it. Examples where ultrathin oxides are proving beneficial include protecting the anode in lithium ion batteries, ${ }^{3-7}$ acting as a passivated contact in novel graphene-silicon Schottky barriers, ${ }^{8}$ in commercially produced passivated emitter and rear cell (PERC) silicon solar cells, ${ }^{9}$ and in applications where efficient visible photoluminescence from silicon-based nanostructures is desirable. ${ }^{10}$ While synthesizing nanometer scale oxide films is a relatively easy task, especially on silicon (e.g., by wet chemical treatments, thermal oxidation, and atomic layer deposition), ${ }^{11-13}$ enhancing their properties to a suitable level is not trivial, and more extensive investigations are necessary to achieve the true potential of ultrathin oxide films.

Received: September 20, 2021

Accepted: December 14, 2021

Published: January 24, 2022 
(a)

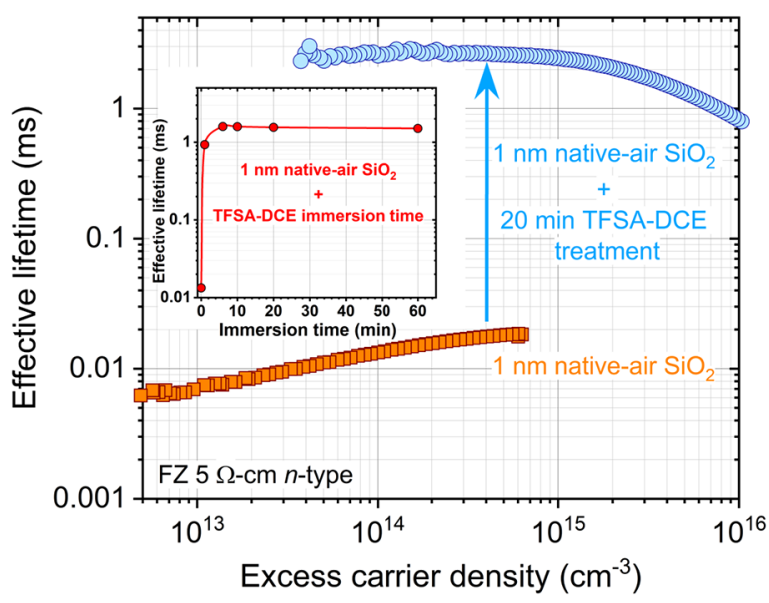<smiles>O=S(=O)(NS(=O)(=O)C(F)(F)F)C(F)(F)F</smiles>

TFSA

$\mathrm{SiO}_{2}$ coated $\mathrm{Si}$ in TFSA solution (b)

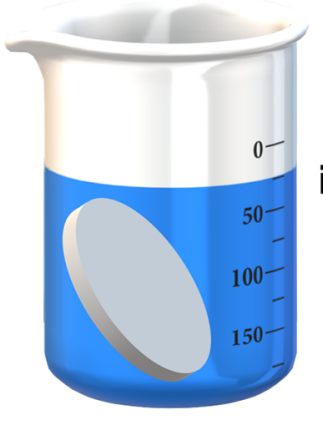

Post TFSA treatment
the sample is stored
in a closed petri-dish

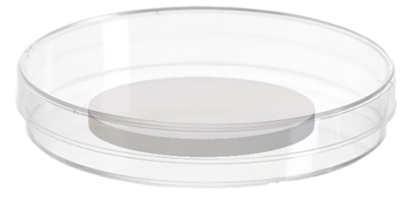

Figure 1. (a) Injection-dependent lifetime of a native-air oxide-coated FZ $5 \Omega \mathrm{cm}$ silicon sample pre-immersion (orange squares) and postimmersion in a TFSA-DCE solution for $20 \mathrm{~min}$ (blue circles). The inset in (a) shows the lifetime improvement with immersion time in the TFSA-DCE solution. (b) Procedure to enhance electrically thin $\mathrm{SiO}_{2}$ layers by first immersing the silicon sample in a TFSA solution followed by storage in a closed plastic Petri dish, which is used during lifetime characterization.

While high-temperature postprocessing methods such as nitrogen/argon annealing are very effective at reducing the dangling bond density at the $\mathrm{Si} / \mathrm{SiO}_{2}$ interface (chemical passivation), ${ }^{11,14}$ the high temperatures pose a risk to the underlying silicon substrate, whereby metal contamination can occur, thereby permanently degrading the silicon material and thus subsequent device performance. Furthermore, unless under vacuum conditions, control of the oxide thickness at elevated temperatures becomes very challenging, as any exposure to oxygen will promote rapid oxide growth, and growing oxides of $\sim 1 \mathrm{~nm}$ or less is extremely challenging. Thus, to minimize further oxide growth (beyond a desirable thickness), low-temperature processing is preferred to enable high levels of surface passivation to be achieved by ultrathin $\mathrm{SiO}_{2}$ films. Suitable methods for this include cesium chloridebased treatments ${ }^{15,16}$ and corona charging. ${ }^{17,18}$ Both of these methods have shown to boost the level of charge contained within the $\mathrm{SiO}_{2}$ film substantially, thereby improving the level of field effect passivation at the $\mathrm{Si} / \mathrm{SiO}_{2}$ interface; however, both require subsequent thermal processing $\left(>400{ }^{\circ} \mathrm{C}\right)$ or dielectric depositions to trap the charge permanently, and such processing can detrimentally affect bulk charge carrier lifetimes. ${ }^{19,20}$

In recent times, however, a temporary room temperature superacid-based treatment has been developed, whereby bare silicon samples are dipped into a solution comprising bis(trifluoromethane)sulfonimide (TFSA or sometimes TFSI) and a solvent such as dichloroethane, hexane, or pentane. $^{21-24}$ With this technique, surface recombination velocities of $<1 \mathrm{~cm} / \mathrm{s}$ (at an injection level $(\Delta n)$ of $10^{15}$ $\mathrm{cm}^{-3}$ ) have been measured, equivalent to the surface passivation achieved by state-of-the-art dielectric films such as silicon nitride, aluminum oxide, or amorphous silicon. ${ }^{25}$ The mechanism of surface passivation has been attributed to a higher degree of chemical passivation compared to the field effect, with the latter providing a minor contribution. ${ }^{23,24}$ However, despite the superacid-based passivation technique showing excellent results on bare silicon samples on a temporary basis, its application on permanently improving the electronic properties of ultrathin $\mathrm{SiO}_{2}$ films has yet to be investigated.

In this work, we apply the superacid-based passivation treatment to ultrathin $\mathrm{SiO}_{2}$ films to modify their electronic properties, with the ultimate aim of establishing permanent surface passivation. We investigate subnanometer $\mathrm{SiO}_{2}$ films produced in different ways, including "native-air" oxides which had grown during prolonged (several years) exposure to ambient air, "native-humid" oxides in which bare silicon surfaces are exposed to a humid atmosphere for several days, and chemically grown "SC2 oxides" arising from standard cleaning processes. We first examine how quickly the oxide passivation increases with immersion time in the superacid solution via photoconductance minority carrier lifetime measurements. We then fit our injection-dependent lifetime data to establish the likely mechanism of passivation, and we measure the composition of the oxides before and after the superacid treatment by X-ray photoelectron spectroscopy (XPS). Investigations into various ultrathin $\mathrm{SiO}_{2}$ growth methods and their corresponding level of passivation achieved post superacid treatment are performed. Finally, we analyze the stability of the superacid solutions and TFSA-solvent interactions via nuclear magnetic resonance (NMR).

\section{RESULTS AND DISCUSSION}

Figure 1a plots the injection-dependent effective lifetime of a native-air $\mathrm{SiO}_{2}$-coated silicon sample pre- and post-immersion in a TFSA-dichloroethane (TFSA-DCE) solution for $20 \mathrm{~min}$ at room temperature. Prior to a superacidic treatment, the measured effective lifetime of the native-air $\mathrm{SiO}_{2}$ coated silicon sample is very low $(\sim 10 \mu \mathrm{s})$ due to a very high surface 

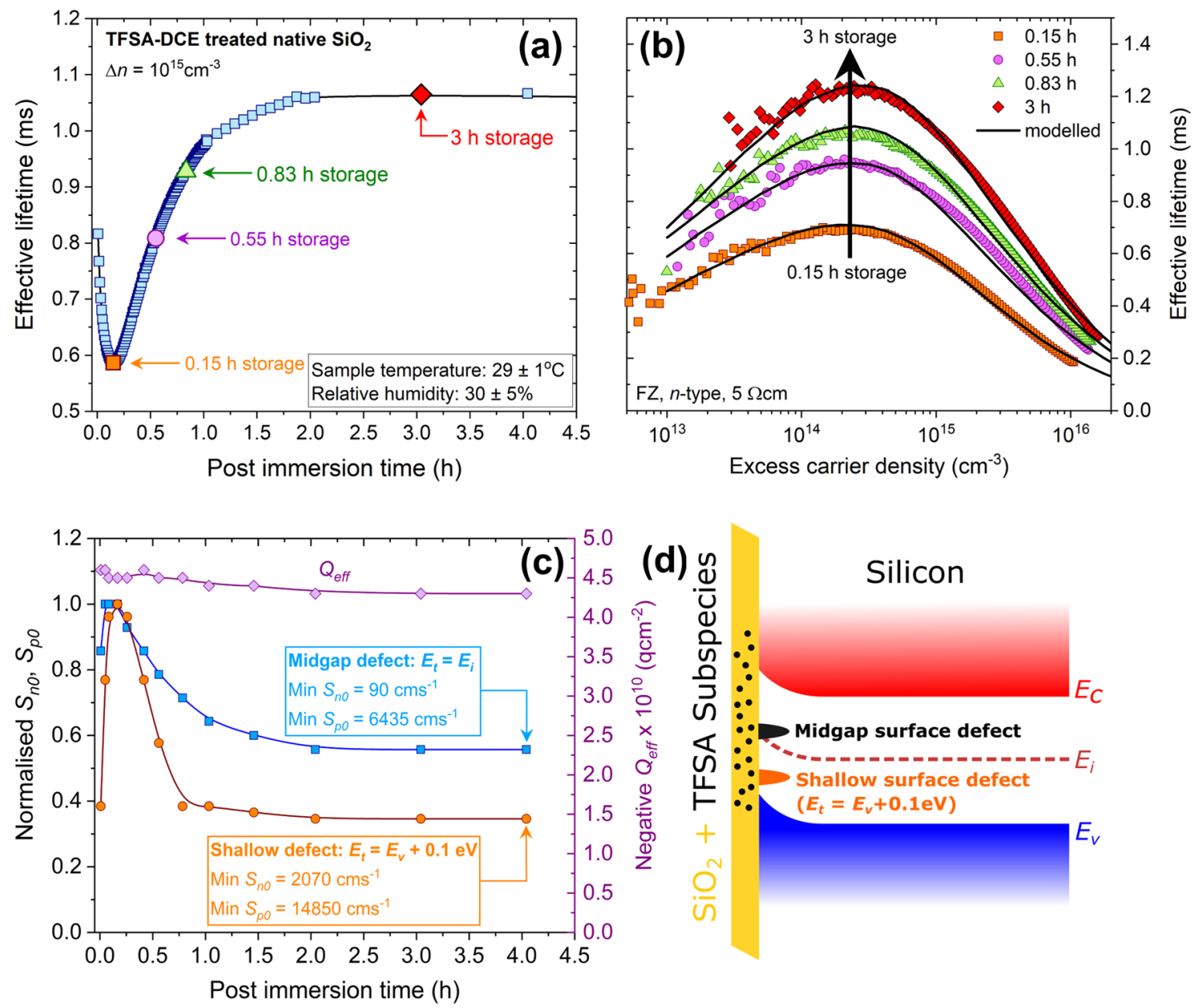

Figure 2. (a) Effective lifetime versus post-immersion time for native-air $\mathrm{SiO}_{2}$-coated $\mathrm{FZ} 5 \Omega \mathrm{cm}$ silicon treated with TFSA-DCE for 20 min. (b) Corresponding injection-dependent effective lifetime at selected time intervals of $0.15,0.55,0.83$, and $3 \mathrm{~h}$, where the solid black lines are the modeled effective lifetime. (c) Normalized $S_{\mathrm{n} 0}, S_{\mathrm{p} 0}$, and $Q_{\text {eff }}$ versus immersion time as determined from the modeled effective lifetime. (d) Energy band diagram showing the likely position of the two dominant defects at the $\mathrm{SiO}_{2} / \mathrm{Si}$ interface as a result of the TFSA treatment.

recombination velocity (SRV) of $\sim 4000 \mathrm{~cm} / \mathrm{s}$, thereby having very little use in applications where power and efficiency are to be maximized.

In contrast, when the same sample is then immersed in a superacidic TFSA-DCE solution, placed into a closed plastic Petri dish (to control the localized ambient conditions), as highlighted in Figure 1b, and subsequently remeasured, we observe a significant increase in the effective lifetime-by greater than 2 orders of magnitude-which corresponds to an upper limit SRV of $<20 \mathrm{~cm} / \mathrm{s}$ (at $\Delta n=10^{15} \mathrm{~cm}^{-3}$ ). Notably, the immersion time can be as short as $5 \mathrm{~min}$, as shown by the inset of Figure 1a; however, a $20 \mathrm{~min}$ immersion time was chosen to ensure maximum passivation was always achieved under open circuit conditions (e.g., no applied bias).

At this point, it is important to mention that our effective lifetime measurements are very sensitive to defects at the $\mathrm{Si}$ / $\mathrm{SiO}_{2}$ interface and charge within the film (including the interface). Thus, by accurately modeling the effective lifetime curves corresponding to the treated $\mathrm{SiO}_{2}$ samples, we can gain further insight on the mechanisms of surface passivation and determine whether chemical species are bonding to defect sites at the $\mathrm{Si} / \mathrm{SiO}_{2}$ interface, thereby reducing the interface state density $D_{\text {it }}$ (chemical passivation), providing a higher level of effective charge $Q_{\text {eff }}$ (field-effect passivation) or a combination of both. Figure 2 shows the results.

Figure 2a shows the effective lifetime of a native-air $\mathrm{SiO}_{2}$ coated Si sample (at $\Delta n=10^{15} \mathrm{~cm}^{-3}$ ) immediately after a 20 min TFSA-DCE treatment. The figure shows the lifetime rapidly degrading, and then after $\sim 15 \mathrm{~min}$, it begins to increase, reaching a stabilized lifetime after $\sim 2 \mathrm{~h}$ post TFSADCE treatment. At this time it is difficult to ascertain why this behavior results, but it does suggest the presence of mobile species within the oxide layer. To support this finding, we model recombination parameters at the $\mathrm{Si} / \mathrm{SiO}_{2}$ interface by fitting each individual lifetime curve, with the quality of fit demonstrated in Figure 2b. Fitting of the experimental lifetime curves was performed by using software available from $\mathrm{PV}$ Lighthouse, ${ }^{26}$ which is based on a method described by Girisch et al. $^{27}$ and subsequently extended by Aberle et al. ${ }^{28}$ For the fitting we use the intrinsic recombination parametrization of Richter et al. $^{29}$ and assume that surface recombination is governed by two defects, one at midgap and the other at $E_{\mathrm{t}}=$ $E_{\mathrm{v}}+0.1 \mathrm{eV}$, as depicted in Figure 2d. The fit parameter for chemical passivation is a carrier type-specific surface recombination parameter; for electrons $\mathrm{S}_{n 0}=\nu_{\mathrm{tn}} \times \sigma_{\mathrm{n}} \times D_{\text {it }}$ and for holes $S_{\mathrm{p} 0}=\nu_{\mathrm{tp}} \times \sigma_{\mathrm{p}} \times D_{\mathrm{it}}$, where $\nu_{\mathrm{tn}}$ is the thermal velocity of electrons, $\nu_{\mathrm{tp}}$ is the thermal velocity of holes, and $\sigma_{\mathrm{n}}$ 

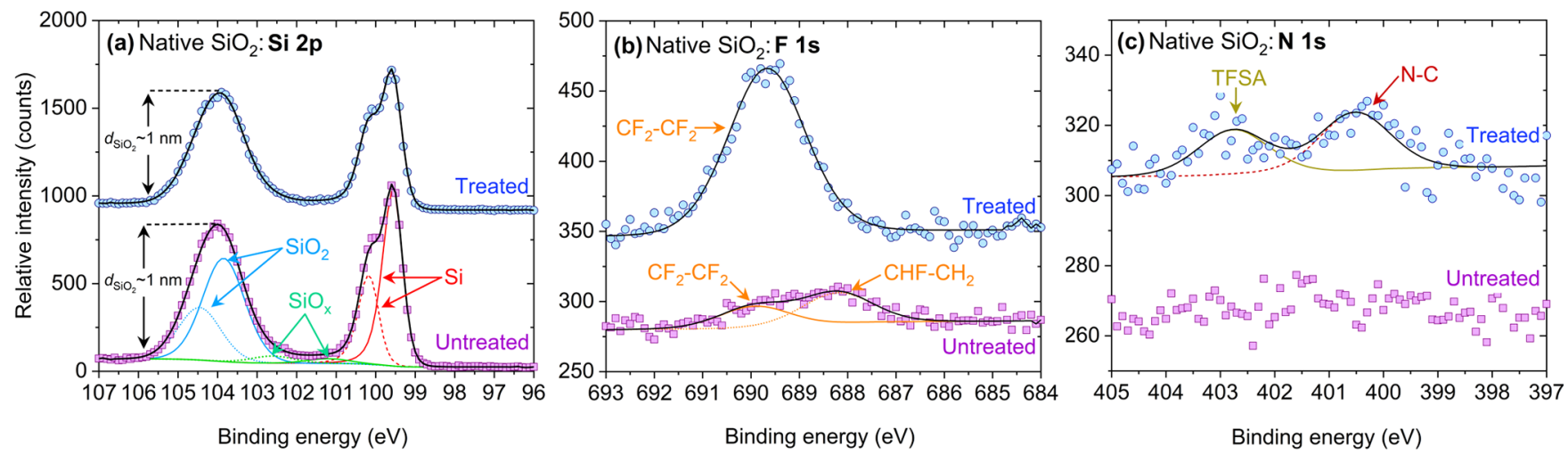

Figure 3. XPS spectra recorded at a takeoff angle of $15^{\circ}$ with respect to the surface parallel for native-air $\mathrm{SiO}_{2}$-coated $\mathrm{FZ} 5 \Omega \mathrm{cm}$ silicon samples without treatment (pink squares) and with treatment in a TFSA-DCE solution for 20 min (blue circles). (a), (b)) and (c) correspond to XPS spectra for Si 2p, F 1s, and N 1s, respectively.

and $\sigma_{\mathrm{p}}$ are the capture cross sections for electrons and holes, respectively. It is not possible to separate the cross section and interface state density terms from the analysis of lifetime data alone.

Figure $2 \mathrm{c}$ shows the trends in the surface recombination parameters resulting from fitting the experimental lifetime curves, as demonstrated in Figure 2b. From our modeling, it can be seen that $Q_{\text {eff }}$ remains relatively constant at $(-4.4 \pm$ $0.1) \times 10^{10} \mathrm{qcm}^{-2}$, thereby confirming that variations (or lack of) in the field-effect passivation cannot explain the rapid degradation and subsequent recovery in lifetime as shown in Figure 2a. Notably, the magnitude of charge and its polarity is consistent with previous Kelvin probe studies of TFSA-based passivation of silicon; however, in those cases, no oxide was present. ${ }^{30}$ With this in mind, we can conclude that the variation in lifetime (i.e., degradation + recovery) is primarily determined by variations in the chemical passivation component (i.e., $S_{\mathrm{n} 0}$ and $S_{\mathrm{p} 0}$ ) at the $\mathrm{Si} / \mathrm{SiO}_{2}$ interface. Figure 2c plots the normalized $S_{\mathrm{n} 0}$ and $S_{\mathrm{p} 0}$ values for the shallow and midgap defects, which in contrast to the trend in $Q_{\text {eff }}$ show marked similarities to the lifetime data in Figure 2a, noting that the lifetime is inversely proportional to surface recombination. In this case, it was appropriate to normalize the $S_{\mathrm{n} 0}$ and $S_{\mathrm{p} 0}$ values as their absolute values differed substantially, and thus their respective trends were difficult to assess. Nevertheless, the reader can extract the absolute values by using the minimum $S_{\mathrm{n} 0}$ and $S_{\mathrm{p} 0}$ values shown in Figure 2c.

While both defects (shallow and midgap) show similar trends in their respective $S_{\mathrm{n} 0}$ and $S_{\mathrm{p} 0}$ parameters, the shallow defect exhibits much stronger recombination activity, evident by the absolute values shown in Figure $2 c$, and therefore the lifetime is predominantly determined by the recombination activity of the shallow defect. Supporting our finding, Zeng et al. reported a reduction in $D_{i t}$ (from current-voltage measurements) when subjecting zirconium oxide $\left(\mathrm{ZrO}_{2}\right)$ coated indium arsenide (InAs) ribbons to a superacid treatment, postulating the reduction in $D_{\text {it }}$ was attributed to hydrogen ions $\left(\mathrm{H}^{+}\right)$diffusing through the $\mathrm{ZrO}_{2}$ layer, which subsequently reduced the interfacial oxide $\left(\mathrm{InO}_{3}\right)$ at the $\mathrm{ZrO}_{2} /$ InAs interface. ${ }^{31}$

Knowing that our superacid treatment primarily enhances surface passivation by reducing the $D_{i t}$, we have performed XPS measurements on our nanometer scale $\mathrm{SiO}_{2}$ films to ascertain the likely chemical species passivating defects at the $\mathrm{Si} / \mathrm{SiO}_{2}$ interface. Figure 3 plots the key XPS features of a native-air $\mathrm{SiO}_{2}$ before and after a 20 min superacidic TFSADCE treatment, with typical survey scans given in Figure S5. From the $\mathrm{Si} 2 \mathrm{p}$ spectra in Figure 3a, two important observations can be drawn. First, an $\sim 1 \mathrm{~nm}$ thick oxide film (as determined by the thickogram method ${ }^{32}$ ) can be observed, consistent with the findings of Morita et al. ${ }^{1}$ for a native oxide, with a chemical structure being predominantly $\mathrm{SiO}_{2}$ and a much smaller percentage being composed of $\mathrm{SiO}_{x}$. Second, the thickness of the native-air $\mathrm{SiO}_{2}$ layer has not reduced postimmersion in a superacidic TFSA-DCE solution. The latter is an important finding, as it indicates the superacid does not etch silicon dioxide and therefore cannot explain the significant increase in effective lifetime (reduction in SRV) in Figure 1a. The XPS spectra in Figures $3 b$ and $3 c$ are for $F$ ss and N 1s, respectively, and these elements are important as they are constituents of the TFSA molecule (shown in Figure 1b). Figure $3 \mathrm{~b}$ clearly demonstrates an increase of fluorine species in the native-air $\mathrm{SiO}_{2}$ layer post TFSA-DCE treatment, with the residual fluorine in the untreated case likely to arise from an etching step earlier in the sample's processing history. We even see small traces of TFSA in the N 1s spectra of Figure 3c. ${ }^{33}$ A similar finding was also observed for a much thinner $(0.3 \mathrm{~nm}) \mathrm{SC} 2 \mathrm{SiO}_{2}$ when treated by a TFSA-DCE solution with the results presented in Figure S1. Further XPS data for O 1s and $\mathrm{C} 1 \mathrm{~s}$ are given in Figures S3 and S4, respectively.

Given the results in Figure 3, it is still unclear how the TFSA molecule reacts when in contact with an $\mathrm{SiO}_{2}$ surface in open circuit conditions. Some reports have evidenced that TFSA can decompose when in contact with silicon-containing surfaces; $^{34,35}$ however, these studies have been performed under bias. Nevertheless, to gain some insight into the behavior of TFSA when in contact with an $\mathrm{SiO}_{2}$ surface under open circuit conditions, we compare XPS spectra recorded at a takeoff angle relative to the surface parallel of $15^{\circ}$ (surface sensitive) and $90^{\circ}$ (bulk sensitive) of relevant elements, with the data presented in Table 1. For the pretreated native-air $\mathrm{SiO}_{2} \mathrm{XPS}$ data shown in Table 1 , there are obvious differences in the $\mathrm{Si}$ and $\mathrm{O}$ concentrations when performing measurements at $15^{\circ}$ and $90^{\circ}$, but they do not change substantially post TFSA treatment. In contrast, the fluorine XPS data show that prior to the superacidic treatment there is a small concentration of $\mathrm{F}$ which is evenly distributed throughout the oxide film, evident by comparing the surface sensitive $15^{\circ}$ measurement, to that of the bulk sensitive $90^{\circ}$ measurement. This residual $\mathrm{F}$ has likely originated from the wet chemical cleaning process once the 
Table 1. XPS Elemental Composition (at. \%) of Native-Air $\mathrm{SiO}_{2}$ Layers Pre and Post TFSA-DCE Treatment at a TakeOff Angle of $15^{\circ}$ and $90^{\circ}$

\begin{tabular}{lcccrc}
\multicolumn{1}{c}{ sample } & $\begin{array}{c}\text { take-off angle } \\
(\mathrm{deg})\end{array}$ & $\mathrm{Si}$ & $\mathrm{O}$ & \multicolumn{1}{c}{$\mathrm{C}$} & $\mathrm{F}$ \\
\hline native-air $\mathrm{SiO}_{2}$ & 90 & 54.5 & 36.8 & 8.4 & 0.3 \\
native-air $\mathrm{SiO}_{2}$ & 15 & 42.6 & 40.2 & 16.9 & 0.3 \\
native-air $\mathrm{SiO}_{2}+$ TFSA & 90 & 54.8 & 38.2 & 6.3 & 0.8 \\
native-air $\mathrm{SiO}_{2}+$ TFSA & 15 & 40.5 & 43.1 & 14.4 & 1.2 \\
\hline
\end{tabular}

wafers had been sliced from the silicon ingot. When the nativeair $\mathrm{SiO}_{2}$ film has been treated with TFSA, there is an increase (relative to the pretreated data in Table 1) in the $\mathrm{F}$ concentration throughout the oxide, with a slightly higher concentration being observed on the surface of the oxide (i.e., $15^{\circ}$ measurement) compared to that observed in the bulk of the $\mathrm{SiO}_{2}$ film (i.e., $90^{\circ}$ measurement). The same finding was observed for the much thinner $\mathrm{SC} 2 \mathrm{SiO}_{2}$ film, as evidenced in Figure S1b and Table S2. In contrast, traces of sulfur in the oxide (or its surface) could not be accurately measured, as the Si 2 s plasmon loss features coincide with the relevant sulfur peaks (e.g., S, C-S-C, and $\mathrm{SO}_{2}-\mathrm{C}$ ) in the XPS spectra. On the other hand, we did detect a moderate signal from carbon; however, carbon is a well-known contaminant that readily absorbs onto the oxide surface under atmospheric conditions (as our samples experienced prior to XPS). Thus, it is difficult to distinguish the remaining atmospheric contamination from carbon in the sample; however, we can rule out the existence of
$\mathrm{SiC}$ as there was no component in the $\mathrm{C} 1 \mathrm{~s}$ spectrum as a binding energy below $284 \mathrm{eV}^{36}$ Thus, on the basis of our compositional analysis of the TFSA treated $\mathrm{SiO}_{2}$ films, fluorine is a strong candidate for the chemical passivation of defects at the $\mathrm{Si} / \mathrm{SiO}_{2}$ interface; however, hydrogen cannot be ruled out, as this too is a constituent of TFSA but challenging to detect. Therefore, while we cannot definitively conclude that TFSA decomposes on the $\mathrm{SiO}_{2}$ surface under open circuit conditions, there are indications from our XPS and lifetime measurements that make it plausible.

Thus far, the main focus of this paper has been on the passivation mechanisms at the silicon-native oxide interface. Now we assess the impact of varying the solvent in which the TFSA is dissolved and the growth method of subnanometer $\mathrm{SiO}_{2}$ films. Figure $4 \mathrm{a}$ plots the effective lifetime at $\Delta n=10^{15}$ $\mathrm{cm}^{-3}$ of a native-air $\mathrm{SiO}_{2}$ coated $\mathrm{Si}$ sample immediately after a 20 min treatment in TFSA-DCE, TFSA-IPA, and TFSApentane. Clear differences in the lifetime trends are observed, suggesting the solvent has a strong influence on how the TFSA molecule reacts with either the $\mathrm{SiO}_{2}$ film or the solvent itself.

While the trends for the TFSA-DCE and TFSA-IPA samples are very similar, the latter begins to degrade rapidly once it had transitioned through the degradation + recovery phase. In contrast, the TFSA-pentane treated $\mathrm{SiO}_{2}$ film shows a very small improvement in the lifetime post treatment for at least $1 \mathrm{~h}$ and then steadily increases, reaching a stabilized lifetime $\sim 40 \mathrm{~h}$ post treatment. While it is not clear why the superacidic treatment should depend on the solvent, there are notable differences in their molecular polarities and chemical
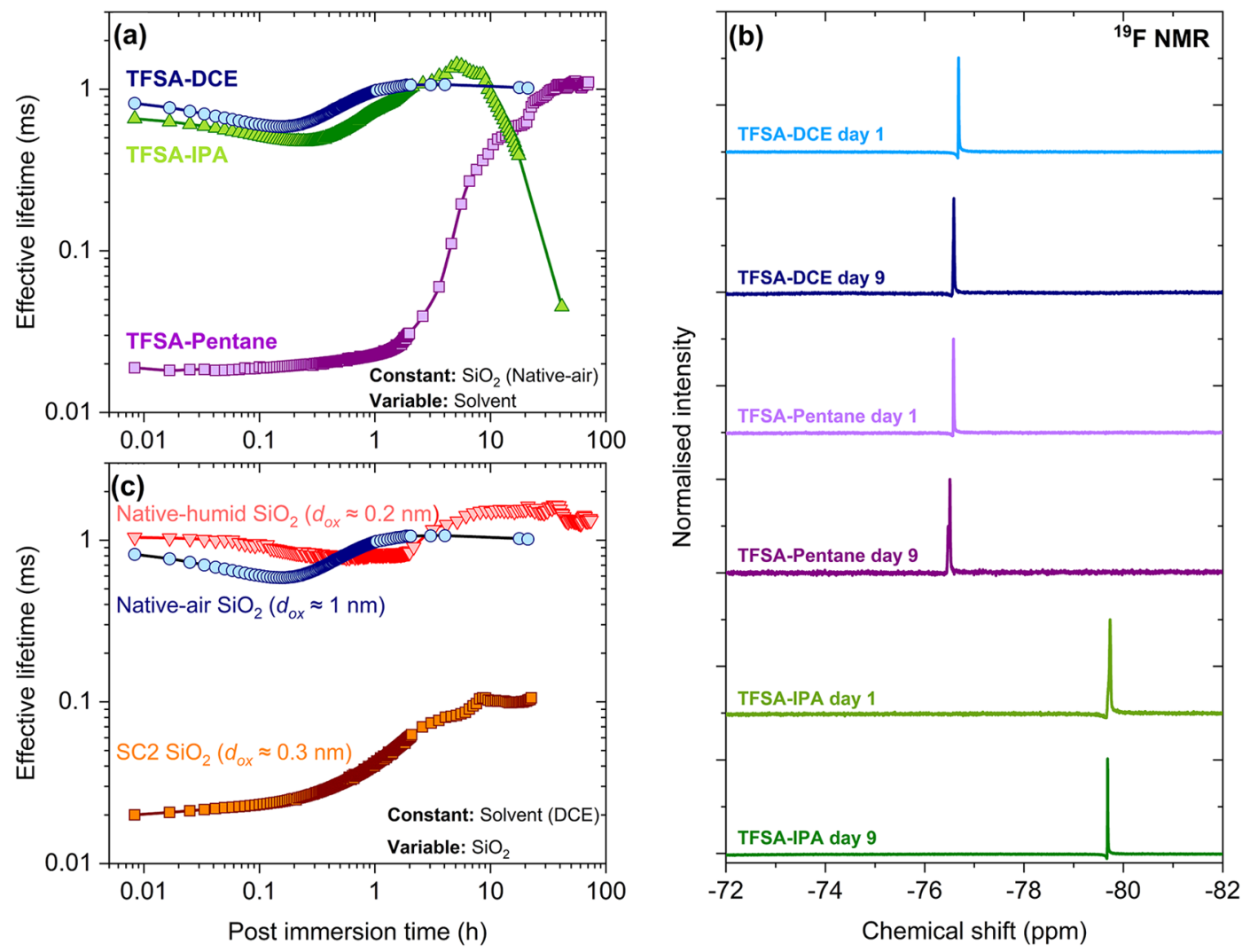

Figure 4. (a) Effective lifetime versus post-immersion time for TFSA-DCE (blue circles), TFSA-IPA (green triangles), and TFSA-pentane (purple squares) treated native-air $\mathrm{SiO}_{2}$-coated $\mathrm{FZ} 5 \Omega \mathrm{cm}$ silicon. (b) ${ }^{19} \mathrm{~F}\left\{{ }^{1} \mathrm{H}\right\}$ NMR spectra for TFSA-DCE, TFSA-IPA, and TFSA-pentane solutions. (c) Effective lifetime versus post-immersion time for TFSA-DCE treated native-air $\mathrm{SiO}_{2}$ (blue circles), native-humid $\mathrm{SiO}_{2}$ (red triangles), and SC2 $\mathrm{SiO}_{2}$ (gold squares) coated FZ $5 \Omega \mathrm{cm}$ silicon. Lifetimes are reported at $\Delta n=10^{15} \mathrm{~cm}^{-3}$. 
makeup. For example IPA, DCE, and pentane have relative molecular polarities of $0.546,0.327$, and 0.009 , respectively, ${ }^{37}$ while IPA is the only solvent which contains an oxygen atom. Similarly, DCE is the only solvent that contains $\mathrm{Cl}$, yet the latter does not show signs of significant instability once the lifetime has recovered. Thus, to clarify this stability issue as seen in Figure 4a, time-dependent ${ }^{19} \mathrm{~F}\left\{{ }^{1} \mathrm{H}\right\}$ NMR was performed on freshly prepared TFSA-solvent mixtures to assess their stability, and results are plotted in Figure $4 \mathrm{~b}$. In general, ${ }^{19} \mathrm{~F}$ NMR spectra of TFSA-containing solutions give rise to a chemical shift of $-76 \pm 1 \mathrm{ppm},{ }^{38}$ which accounts for most solvent interactions with the TFSA anion, and this is confirmed by our measurements of TFSA-DCE and TFSApentane shown in Figure $4 \mathrm{~b}$. In contrast, TFSA-IPA shows a chemical shift of $\sim-80 \mathrm{ppm}$, which is $\sim 3 \mathrm{ppm}$ more negative than for TFSA-DCE and TFSA-pentane, indicating that the TFSA's fluorine atoms are more shielded in the TFSA-IPA solution than in other solutions, thereby causing a more negative chemical shift of the TFSA peak in the ${ }^{19} \mathrm{~F}$ NMR spectra. As noted above, IPA is the only solvent that contains oxygen, and thus the electron-donating ability of the oxygen could explain why we see more shielding (e.g., a more negative chemical shift of the TFSA peak) in the ${ }^{19} \mathrm{~F}$ NMR spectra compared to TFSA-DCE and TFSA-pentane. To further evidence this theory, Figure 5 plots the chemical shift of the

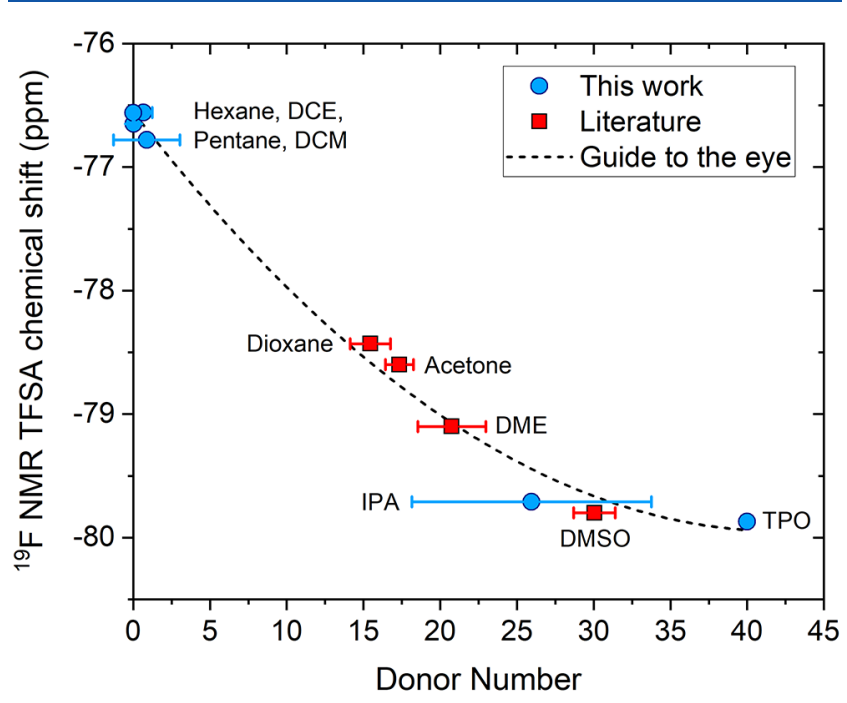

Figure 5. ${ }^{19} \mathrm{~F}$ NMR chemical shift of the TFSA anion versus the donor number of the solvents in which the TFSA anion was dissolved. The blue circles represent values that have been measured in this work, and the red squares correspond to data in the literature. ${ }^{39-45}$ The black dashed line is a guide to the eye.

TFSA anion as a function of donor number, a quantitative measure of electron-donating ability, ${ }^{39}$ for a variety of solvents in which the TFSA anion was dissolved.

Figure 5 plots the ${ }^{19} \mathrm{~F}$ NMR chemical shift of TFSA dissolved in various solvents. The blue circles correspond to measurements we have performed, and the red squares represent data from the literature. ${ }^{39-45}$ From the figure, it is evident that a monotonic trend in the TFSA chemical peak shift with donor number exists, with oxygenated solvents tending to have higher donor numbers, suggesting the oxygen in the solvent does influence interactions with the TFSA anion. In the context of Figure $4 \mathrm{~b}$, we note that while TFSA-IPA interactions are present (presumably due to the presence of oxygen in the solvent), we do not see any evidence of the TFSA anion breaking down into subspecies over a 9 day period, and therefore instabilities observed for the TFSA-IPA sample in Figure 4a (green triangles) cannot be attributed to this.

Therefore, on the basis of evidence we have acquired, we can only postulate that the electron-donating properties of oxygenated IPA are negatively impacting the stability of the surface passivation (by yet an unknown mechanism) when a native oxide film is treated by a TFSA-IPA solution. Thus, to overcome instability issues when treating ultrathin $\mathrm{SiO}_{2}$ films in TFSA-based solutions, it is best to avoid solvents that contain a high electron-donating number (e.g., like those shown in Figure 5).

In contrast to varying the solvent and observing its influence on the level (and stability) of surface passivation attained post superacidic treatment, we have also examined the influence of the $\mathrm{SiO}_{2}$ growth method (as specified in the Methods section). Figure $4 \mathrm{c}$ plots the effective lifetime (at $\Delta n=10^{15} \mathrm{~cm}^{-3}$ ) of TFSA-DCE treated native-humid $\mathrm{SiO}_{2}$ (4 day growth time), SC2 $\mathrm{SiO}_{2}$, and native-air $\mathrm{SiO}_{2}$ (as a reference). All oxide thicknesses were determined by the thickogram method using XPS peak intensity data. ${ }^{32}$

From Figure $4 c$, it is quite clear that the level of surface passivation is not dependent on the oxide thickness, evident by comparing the native-humid $\mathrm{SiO}_{2}$ and native-air $\mathrm{SiO}_{2}$ lifetime trends, with the former having an oxide thickness of $\sim 0.2 \mathrm{~nm}$ and the latter $\sim 1 \mathrm{~nm}$. In contrast, the $\mathrm{SC} 2 \mathrm{SiO}_{2}$ and nativehumid $\mathrm{SiO}_{2}$ samples have similar oxide thicknesses, yet their corresponding lifetime levels (and passivation quality) differ by almost 2 orders of magnitude. While XPS data (see Tables S1 and S2) do show slight variations in the chemical makeup of these oxides (e.g., varying levels of carbon, oxygen, and fluorine), there is not sufficient data to draw the main differences in the chemical makeup of the oxides (e.g., atomic/ molecular hydrogen) conclusively, yet it is clear they play a significant role. Thus, while no conclusions can be drawn from the differing passivation behavior of the various oxides post TFSA-DCE treatment, it is clear that the growth method and not the oxide thickness (when $d_{\mathrm{ox}} \leq 1 \mathrm{~nm}$ ) is key to achieving a high level of surface passivation.

\section{CONCLUSION}

In this work, we have demonstrated that the surface passivation offered by ultrathin $\mathrm{SiO}_{2}$ films can be substantially enhanced by subjecting the films to a short wet chemical superacid-based immersion treatment at room temperature. By accurately modeling the effective lifetime curves corresponding to the superacid treated $\mathrm{SiO}_{2}$ samples, we have determined that the enhanced passivation is mainly due to a reduction in the interface defect density at the $\mathrm{Si} / \mathrm{SiO}_{2}$ interface, with a minor contribution also arising from the presence of negative charge. Subsequent XPS measurements of the treated $\mathrm{SiO}_{2}$ films revealed the presence of fluorine, and this, along with hydrogen, is a strong candidate for the chemical passivation of defects at the $\mathrm{Si} / \mathrm{SiO}_{2}$ interface. Importantly, the XPS results also demonstrated that the ultrathin oxide films are not etched when subject to superacid solutions. Post treatment, the $\mathrm{SiO}_{2}$ films show short time scale electronic instability, whereby a degradation and then recovery are observed over a period of $1-10 \mathrm{~h}$ which has been attributed to variations in the chemical passivation, while the field effect passivation component remains relatively stable. Following the instability period, the 
surface passivation (chemical and field effect) remains relatively stable; however, in cases where the $\mathrm{SiO}_{2}$ films have been treated by a superacid solution that enhances electron donation (e.g., TFSA dissolved in oxygen-containing solvents), a permanent degradation trend is observed, suggesting oxygencontaining solvents should be avoided. Finally, we demonstrated that the oxide growth method, and not its thickness (for $d_{\text {ox }} \leq 1 \mathrm{~nm}$ ), plays a significant role in the level of surface passivation that can be achieved post superacid treatment, whereby native oxide films show the most promising results compared to those oxides grown via standard wet chemical processes.

\section{METHODS}

Experiments were conducted on $700 \mu \mathrm{m}$ thick $5 \Omega \mathrm{cm}$ n-type (100)orientation $100 \mathrm{~mm}$ diameter float-zone (FZ) silicon wafers. Prior to oxidation of the silicon surface, the samples (aside from samples which necessitated a native-air oxide to remain) were subjected to a carefully optimized surface preparation process ${ }^{22,23}$ comprising an $\mathrm{HF}$ (1\%) dip, standard clean $2 \mathrm{SC} 2\left(\mathrm{H}_{2} \mathrm{O}, \mathrm{H}_{2} \mathrm{O}_{2}(30 \%)\right.$, and $\mathrm{HCl}(37 \%)$ in 5:1:1 ratio) for $10 \mathrm{~min}$ at $\sim 75{ }^{\circ} \mathrm{C}$, an $\mathrm{HF}$ (1\%) dip, an etch in $25 \%$ tetramethylammonium hydroxide (TMAH) for $10 \mathrm{~min}$ at $\sim 80{ }^{\circ} \mathrm{C}$, another HF (1\%) dip, and a second standard clean 2 as previously described, followed by immersion in $2 \%$ HF. Samples are then pulled dry from the HF solution.

In this work three different types of silicon dioxide films were investigated: (i) native-air oxide which had grown during prolonged (several years) exposure to ambient air while being stored in a wafer box (these samples did not go through the chemical pretreatment); (ii) native-humid oxide were grown by exposing the bare silicon surface to an $85-90 \% \mathrm{RH}$ ambient air at $\sim 20^{\circ} \mathrm{C}$ for $1-10$ days (see growth rate data in Figure S2); and (iii) SC2 oxide were grown by using a standard clean 2 solution as specified above for $10 \mathrm{~min}$ at $\sim 75$ ${ }^{\circ} \mathrm{C}$.

Precursor chemicals were handled and stored in a high specification glovebox (a sealed filtered MBRAUN UNIlab modular glovebox workstation) with gas purification system and solvent filter with a controlled low-humidity atmosphere $\left(<0.1 \mathrm{ppm}\right.$ of $\mathrm{O}_{2} ;<0.1 \mathrm{ppm}$ of $\mathrm{H}_{2} \mathrm{O}$ ). Superacidic solutions were made by dissolving $400 \mathrm{mg}$ of bis(trifluoromethane)sulfonimide (TFSA) crystals from SigmaAldrich ( $>95 \%$ purity) in $200 \mathrm{~mL}$ of either anhydrous pentane ( $>99 \%$ pure), anhydrous 1,2-dichloroethane (DCE, 99.8\% pure), or anhydrous 2-propanol ( $99.5 \%$ pure) from Sigma-Aldrich. The solutions were then transferred to a lower specification glovebox with a flowing nitrogen ambient atmosphere (relative humidity $<25 \%$ ). For each experiment, solutions were poured into a glass beaker, and a $\mathrm{SiO}_{2}$-coated silicon sample was immersed into the solution for $20 \mathrm{~min}$ unless otherwise specified. Following the superacidic treatment, the samples were allowed to dry in the glovebox, placed into closed plastic Petri dishes, and removed from the glovebox for characterization purposes. Quasi-steady-state photoconductance (QSSPC) and transient photoconductance decay (PCD) lifetime measurements were performed by using a Sinton WCT-120 lifetime tester.

The superacidic solutions were studied by nuclear magnetic resonance (NMR) with ${ }^{19} \mathrm{~F}\left\{{ }^{1} \mathrm{H}\right\}$ NMR spectra recorded on a Bruker Avance III HD 300 at $282.4 \mathrm{MHz}$. Sample tubes were filled with deuterated chloroform ( $>99.8 \%$ purity with $0.03 \%$ tetramethylsilane) under a dry nitrogen atmosphere. $\alpha, \alpha, \alpha$-trifluorotoluene $(\delta \mathrm{F}-63.72$ $\mathrm{ppm})$ was added as an internal fluorine reference. All spectra were averaged over 64 scans.

Photoelectron spectroscopy data were collected at the Warwick Photoemission Facility using a Kratos Axis Ultra DLD spectrometer. Treated samples were mounted on to copper stubs by using electrically conductive carbon tape and transferred to the spectrometer from a glovebox under an inert atmosphere. The base pressure of the XPS spectrometer was $\sim 1 \times 10^{-10} \mathrm{mbar}$, and samples were pumped to below $1 \times 10^{-6} \mathrm{mbar}$ in the load lock before transfer.
XPS measurements were performed by using a monochromated $\mathrm{Al}$ $\mathrm{K} \alpha \mathrm{X}$-ray source. The measurements were conducted at room temperature and at a takeoff angle of $15^{\circ}$ and $90^{\circ}$ with respect to the surface parallel. The core level XPS spectra were recorded by using a pass energy of $20 \mathrm{eV}$ (resolution $\sim 0.4 \mathrm{eV}$ ) from an analysis area of $300 \mu \mathrm{m} \times 700 \mu \mathrm{m}$. The spectrometer work function and binding energy scale were calibrated by using the Fermi edge and $3 \mathrm{~d}_{5 / 2}$ peak recorded from a polycrystalline $\mathrm{Ag}$ sample prior to the commencement of the experiments. Fitting procedures to extract peaks positions and relative stoichiometries from the XPS data were performed by using the Casa XPS software suite, Shirley backgrounds, and mixed Gaussian-Lorentzian (Voigt) line shapes, and the oxide thicknesses were calculated by using the thickogram method, ${ }^{32}$ with the corresponding sensitivity factors given in Table S3.

\section{ASSOCIATED CONTENT}

\section{(s) Supporting Information}

The Supporting Information is available free of charge at https://pubs.acs.org/doi/10.1021/acsaem.1c02935.

XPS spectra of treated and untreated $\mathrm{SC} 2 \mathrm{SiO}_{2}$ films, $\mathrm{SiO}_{2}$ thickness versus growth time information, XPS O $1 \mathrm{~s}$ and C 1s spectra, XPS survey scans, tables of XPS elemental composition, and tables of sensitivities parameters used in thickogram calculations (PDF)

\section{AUTHOR INFORMATION}

\section{Corresponding Author}

Nicholas E. Grant - School of Engineering, University of Warwick, Coventry CV4 7AL, United Kingdom;

(1) orcid.org/0000-0002-3943-838X;

Email: nicholas.e.grant@warwick.ac.uk

\section{Authors}

Sophie L. Pain - School of Engineering, University of Warwick, Coventry CV4 7AL, United Kingdom; ๑ orcid.org/0000-0003-1333-2023

Joshua T. White - Department of Chemistry, University of Warwick, Coventry CV4 7AL, United Kingdom

Marc Walker - Department of Physics, University of Warwick, Coventry CV4 7AL, United Kingdom

Ivan Prokes - Department of Chemistry, University of Warwick, Coventry CV4 7AL, United Kingdom

John D. Murphy - School of Engineering, University of Warwick, Coventry CV4 7AL, United Kingdom; ๑ orcid.org/0000-0003-0993-5972

Complete contact information is available at:

https://pubs.acs.org/10.1021/acsaem.1c02935

\section{Author Contributions}

N.E.G., J.D.M., and S.L.P. developed the ideas for the experiments and established the principal objectives of the work. N.E.G. and J.T.W. performed superacidic treatments and subsequent lifetime measurements. S.L.P. designed NMR studies and interpreted data, with NMR experimental work being performed by S.L.P. and I.P. M.W. performed XPS experiments and analyzed/interpreted data with N.E.G. The manuscript was written by N.E.G., with input from J.D.M. and S.L.P., and all authors commented upon it.

\section{Funding}

This work was funded by the EPSRC SuperSilicon PV project (EP/M024911/1), the EPSRC Impact Acceleration Account (EP/R511808/1), and the EPSRC Charged Oxide Inversion Layer (COIL) Solar Cells project (EP/V037749/1). S.L.P. was 
funded by an EPSRC Doctoral Training Partnership grant (EP/R513374/1), and J.T.W. was funded by the EPSRC Centre for Doctoral Training in Molecular Analytical Science (EP/L015307/1).

\section{Notes}

The authors declare no competing financial interest.

Data underpinning figures in this paper can be freely downloaded from http://wrap.warwick.ac.uk/161188/. Requests for additional data should be made directly to the corresponding author.

\section{REFERENCES}

(1) Morita, M.; Ohmi, T.; Hasegawa, E.; Kawakami, M.; Ohwada, M. Growth of native oxide on a silicon surface. J. Appl. Phys. 1990, 68 (3), 1272-1281.

(2) Matteini, F.; Tütüncüoglu, G.; Potts, H.; Jabeen, F.; Fontcuberta i Morral, A. Wetting of $\mathrm{Ga}$ on $\mathrm{SiO}_{\mathrm{x}}$ and Its Impact on GaAs Nanowire Growth. Cryst. Growth Des. 2015, 15 (7), 3105-3109.

(3) Kong, K.; Xu, G.; Lan, Y.; Jin, C.; Yue, Z.; Li, X.; Sun, F.; Huang, $\mathrm{H}$.; Yuan, J.; Zhou, L. Effect of $\mathrm{SiO}_{\mathrm{x}}$-coating crystallinity on electrochemical performance of $\mathrm{Si} @ \mathrm{SiO}_{\mathrm{x}}$ anode materials in lithiumion batteries. Appl. Surf. Sci. 2020, 515, 146026.

(4) Song, J.-W.; Nguyen, C. C.; Song, S.-W. Stabilized cycling performance of silicon oxide anode in ionic liquid electrolyte for rechargeable lithium batteries. RSC $A d v$. 2012, 2, 2003.

(5) Stetson, C.; Schnabel, M.; Li, Z.; Harvey, S. P.; Jiang, C.-S.; Norman, A.; DeCaluwe, S. C.; Al-Jassim, M.; Burrell, A. Microscopic Observation of Solid Electrolyte Interphase Bilayer Inversion on Silicon Oxide. ACS Energy Letters 2020, 5 (12), 3657-3662.

(6) Schnabel, M.; Arca, E.; Ha, Y.; Stetson, C.; Teeter, G.; Han, S.D.; Stradins, P. Enhanced Interfacial Stability of Si Anodes for Li-Ion Batteries via Surface $\mathrm{SiO}_{2}$ Coating. ACS Applied Energy Materials 2020, 3 (9), 8842-8849.

(7) Schnabel, M.; Harvey, S. P.; Arca, E.; Stetson, C.; Teeter, G.; Ban, C.; Stradins, P. Surface $\mathrm{SiO}_{2}$ Thickness Controls Uniform-toLocalized Transition in Lithiation of Silicon Anodes for Lithium-Ion Batteries. ACS Appl. Mater. Interfaces 2020, 12 (24), 27017-27028.

(8) Song, Y.; Li, X.; Mackin, C.; Zhang, X.; Fang, W.; Palacios, T.; $\mathrm{Zhu}, \mathrm{H}$.; Kong, J. Role of Interfacial Oxide in High-Efficiency Graphene-Silicon Schottky Barrier Solar Cells. Nano Lett. 2015, 15 (3), 2104-2110.

(9) Feldmann, F.; Bivour, M.; Reichel, C.; Steinkemper, H.; Hermle, M.; Glunz, S. W. Tunnel oxide passivated contacts as an alternative to partial rear contacts. Sol. Energy Mater. Sol. Cells 2014, 131, 46-50.

(10) Canham, L. Introductory lecture: origins and applications of efficient visible photoluminescence from silicon-based nanostructures. Faraday Discuss. 2020, 222, 10-81.

(11) Grant, N. E.; McIntosh, K. R. Passivation of a (100) Silicon Surface by Silicon Dioxide Grown in Nitric Acid. IEEE Electron Device Lett. 2009, 30 (9), 922-924.

(12) Asuha, H. K.; Maida, O.; Takahashi, M.; Iwasa, H. Nitric acid oxidation of $\mathrm{Si}$ to form ultrathin silicon dioxide layers with a low leakage current density. J. Appl. Phys. 2003, 94 (11), 7328-7335.

(13) Grant, N. E.; Kho, T. C.; Fong, K. C.; Franklin, E.; McIntosh, K. R.; Stocks, M.; Wan, Y.; Wang, E.-C.; Zin, N.; Murphy, J. D.; Blakers, A. Anodic oxidations: Excellent process durability and surface passivation for high efficiency silicon solar cells. Sol. Energy Mater. Sol. Cells 2019, 203, 110155 .

(14) Füssel, W.; Schmidt, M.; Angermann, H.; Mende, G.; Flietner, $\mathrm{H}$. Defects at the $\mathrm{Si} / \mathrm{SiO}_{2}$ interface: Their nature and behaviour in technological processes and stress. Nucl. Instrum. Methods Phys. Res., Sect. A 1996, 377 (2), 177-183.

(15) Bauch, W.; Jäger, K.; Hezel, R. Effect of Cs contamination on the interface state density of MNOS capacitors. Appl. Surf. Sci. 1989, 39 (1), 356-363.

(16) Hezel, R. Recent progress in MIS solar cells. Prog. Photovoltaics 1997, 5 (2), 109-120.
(17) Bonilla, R. S.; Reichel, C.; Hermle, M.; Hamer, P.; Wilshaw, P. $\mathrm{R}$. Long term stability of $\mathrm{c}$-Si surface passivation using corona charged $\mathrm{SiO}_{2}$. Appl. Surf. Sci. 2017, 412, 657-667.

(18) Kho, T. C.; Baker-Finch, S. C.; McIntosh, K. R. The study of thermal silicon dioxide electrets formed by corona discharge and rapid-thermal annealing. J. Appl. Phys. 2011, 109 (5), 053108.

(19) Grant, N. E.; Markevich, V. P.; Mullins, J.; Peaker, A. R.; Rougieux, F.; Macdonald, D. Thermal activation and deactivation of grown-in defects limiting the lifetime of float-zone silicon. Phys. Status Solidi RRL 2016, 10 (6), 443-447.

(20) Grant, N. E.; Markevich, V. P.; Mullins, J.; Peaker, A. R.; Rougieux, F.; Macdonald, D.; Murphy, J. D. Permanent annihilation of thermally activated defects which limit the lifetime of float-zone silicon. Phys. Status Solidi A 2016, 213 (11), 2844-2849.

(21) Bullock, J.; Kiriya, D.; Grant, N.; Azcatl, A.; Hettick, M.; Kho, T.; Phang, P.; Sio, H. C.; Yan, D.; Macdonald, D.; Quevedo-Lopez, M. A.; Wallace, R. M.; Cuevas, A.; Javey, A. Superacid Passivation of Crystalline Silicon Surfaces. ACS Appl. Mater. Interfaces 2016, 8 (36), 24205-24211.

(22) Grant, N. E.; Niewelt, T.; Wilson, N. R.; Wheeler-Jones, E. C.; Bullock, J.; Al-Amin, M.; Schubert, M. C.; van Veen, A. C.; Javey, A.; Murphy, J. D. Superacid-Treated Silicon Surfaces: Extending the Limit of Carrier Lifetime for Photovoltaic Applications. IEEE Journal of Photovoltaics 2017, 7 (6), 1574-1583.

(23) Pointon, A. I.; Grant, N. E.; Wheeler-Jones, E. C.; Altermatt, P. P.; Murphy, J. D. Superacid-derived surface passivation for measurement of ultra-long lifetimes in silicon photovoltaic materials. Sol. Energy Mater. Sol. Cells 2018, 183, 164-172.

(24) Pointon, A. I.; Grant, N. E.; Pain, S. L.; White, J. T.; Murphy, J. D. Sub-2 $\mathrm{cm} / \mathrm{s}$ passivation of silicon surfaces by aprotic solutions. Appl. Phys. Lett. 2020, 116 (12), 121601.

(25) Bonilla, R. S.; Hoex, B.; Hamer, P.; Wilshaw, P. R. Dielectric surface passivation for silicon solar cells: A review. Phys. Status Solidi A 2017, 214 (7), 1700293.

(26) Calculator map on PV Lighthouse. http://www.pvlighthouse. com.au.

(27) Girisch, R. B. M.; Mertens, R. P.; De Keersmaecker, R. F. Determination of $\mathrm{Si}_{-} \mathrm{SiO}_{2}$ interface recombination parameters using a gate-controlled point-junction diode under illumination. IEEE Trans. Electron Devices 1988, 35 (2), 203-222.

(28) Aberle, A. G.; Glunz, S.; Warta, W. Impact of illumination level and oxide parameters on Shockley-Read-Hall recombination at the $\mathrm{Si}-\mathrm{SiO}_{2}$ interface. J. Appl. Phys. 1992, 71 (9), 4422-4431.

(29) Richter, A.; Glunz, S. W.; Werner, F.; Schmidt, J.; Cuevas, A. Improved quantitative description of Auger recombination in crystalline silicon. Phys. Rev. B: Condens. Matter Mater. Phys. 2012, 86 (16), 165202.

(30) Pointon, A. I.; Grant, N. E.; Bonilla, R. S.; Wheeler-Jones, E. C.; Walker, M.; Wilshaw, P. R.; Dancer, C. E. J.; Murphy, J. D. Exceptional Surface Passivation Arising from Bis(trifluoromethanesulfonyl)-Based Solutions. ACS Applied Electronic Materials 2019, 1 (7), 1322-1329.

(31) Zeng, Y.; Khandelwal, S.; Shariar, K. F.; Wang, Z.; Lin, G.; Cheng, Q.; Cui, P.; Opila, R.; Balakrishnan, G.; Addamane, S.; Taheri, P.; Kiriya, D.; Hettick, M.; Javey, A. InAs FinFETs Performance Enhancement by Superacid Surface Treatment. IEEE Trans. Electron Devices 2019, 66 (4), 1856-1861.

(32) Cumpson, P. J. The Thickogram: a method for easy film thickness measurement in XPS. Surf. Interface Anal. 2000, 29 (6), 403-406.

(33) Dietrich, P. M.; Gehrlein, L.; Maibach, J.; Thissen, A. Probing Lithium-Ion Battery Electrolytes with Laboratory Near-Ambient Pressure XPS. Crystals 2020, 10 (11), 1056.

(34) Piper, D. M.; Evans, T.; Leung, K.; Watkins, T.; Olson, J.; Kim, S. C.; Han, S. S.; Bhat, V.; Oh, K. H.; Buttry, D. A.; Lee, S.-H. Stable silicon-ionic liquid interface for next-generation lithium-ion batteries. Nat. Commun. 2015, 6 (1), 6230. 
(35) Nguyen, C. C.; Woo, S.-W.; Song, S.-W. Understanding the Interfacial Processes at Silicon-Copper Electrodes in Ionic Liquid Battery Electrolyte. J. Phys. Chem. C 2012, 116 (28), 14764-14771.

(36) Jensen, D. S.; Kanyal, S. S.; Madaan, N.; Vail, M. A.; Dadson, A. E.; Engelhard, M. H.; Linford, M. R. Silicon (100)/ $/ \mathrm{SiO}_{2}$ by XPS. Surf. Sci. Spectra 2013, 20 (1), 36-42.

(37) Reichardt, C.; Welton, T. Solvent and Solvent Effects in Organic Chemistry, 4th ed.; Wiley-VCH: 2011.

(38) Foropoulos, J., Jr.; DesMarteau, D. D. Synthesis, properties, and reactions of bis((trifluoromethyl)sulfonyl) imide, $\left(\mathrm{CF}_{3} \mathrm{SO}_{2}\right)_{2} \mathrm{NH}$. Inorg. Chem. 1984, 23, 3720-3723.

(39) Marcus, Y. The effectivity of solvents as electron pair donors. J. Solution Chem. 1984, 13 (9), 599-624.

(40) Hahn, S.; Miller, W. M.; Lichtenthaler, R. N.; Prausnitz, J. M. Donor Number Estimation for Oxygen- and Nitrogen-Containing Solvents via Proton NMR Shift of Chloroform. J. Solution Chem. 1985, 14 (2), 129-137.

(41) Khuthier, A.-H.; Hanna, S. Y.; Al-Mallah, K. Y. Studies of tertiary amine oxides. Part 13. Solvent effects on the rate of thermal rearrangement of $\mathrm{N}$-(2,4-dinitrophenyl)piperidine $\mathrm{N}$-oxide. J. Chem. Soc., Perkin Trans. 2 1988, 7, 1157-1160.

(42) Marzec, A.; Juzwa, M.; Betlej, K.; Sobkowiak, M. Bituminous Coal Extraction in Terms of Electron-Donor and -Acceptor Interactions in the Solvent/Coal System. Fuel Process. Technol. 1979, 2, 35-44.

(43) Rodriguez, M. A.; Rubio, J.; Rubio, F.; Liso, M. J.; Oteo, J. L. Application of Inverse Gas Chromatography to the Study of the Surface Properties of Slates. Clays Clay Miner. 1997, 45 (5), 670-680.

(44) Jache, B.; Binder, J. O.; Abe, T.; Adelhelm, P. A comparative study on the impact of different glymes and their derivatives as electrolyte solvents for graphite co-intercalation electrodes in lithiumion and sodium-ion batteries. Phys. Chem. Chem. Phys. 2016, 18 (21), 14299-316.

(45) Lutz, L.; Yin, W.; Grimaud, A.; Alves Dalla Corte, D.; Tang, M.; Johnson, L.; Azaceta, E.; Sarou-Kanian, V.; Naylor, A. J.; Hamad, S.; Anta, J. A.; Salager, E.; Tena-Zaera, R.; Bruce, P. G.; Tarascon, J. M. High Capacity $\mathrm{Na}-\mathrm{O} 2$ Batteries: Key Parameters for SolutionMediated Discharge. J. Phys. Chem. C 2016, 120 (36), 20068-20076.

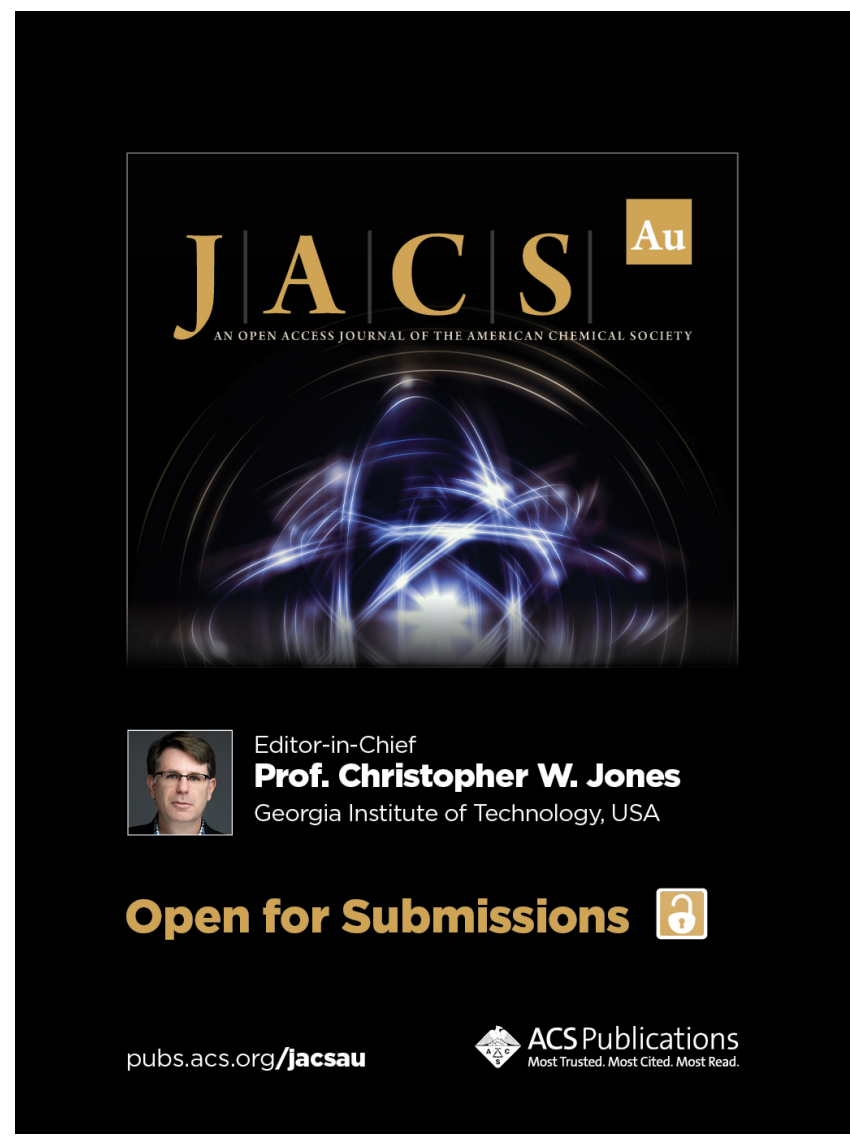

